Article

\title{
Arabidopsis Plastid-RNA Polymerase RPOTp Is Involved in Abiotic Stress Tolerance
}

\author{
Abel Lidón-Soto, Eva Núñez-Delegido, Iván Pastor-Martínez ${ }^{\mathbb{D}}$, Pedro Robles and \\ Víctor Quesada *
}

Instituto de Bioingeniería, Universidad Miguel Hernández, Campus de Elche, 03202 Elche, Spain; abel.lidon@goumh.umh.es (A.L.-S.); eva.nunez@goumh.umh.es (E.N.-D.); ivan.pastor@goumh.umh.es (I.P.-M.); probles@umh.es (P.R.)

* Correspondence: vquesada@umh.es; Tel.: +34-96-665-8812

Received: 10 June 2020; Accepted: 29 June 2020; Published: 2 July 2020

\begin{abstract}
Plastid gene expression (PGE) must adequately respond to changes in both development and environmental cues. The transcriptional machinery of plastids in land plants is far more complex than that of prokaryotes. Two types of DNA-dependent RNA polymerases transcribe the plastid genome: a multimeric plastid-encoded polymerase (PEP), and a monomeric nuclear-encoded polymerase (NEP). A single NEP in monocots (RPOTp, RNA polymerase of the T3/T7 phage-type) and two NEPs in dicots (plastid-targeted RPOTp, and plastid- and mitochondrial-targeted RPOTmp) have been hitherto identified. To unravel the role of PGE in plant responses to abiotic stress, we investigated if Arabidopsis RPOTp could function in plant salt tolerance. To this end, we studied the sensitivity of T-DNA mutants scabra3-2 (sca3-2) and sca3-3, defective in the RPOTp gene, to salinity, osmotic stress and the phytohormone abscisic acid (ABA) required for plants to adapt to abiotic stress. sca3 mutants were hypersensitive to $\mathrm{NaCl}$, mannitol and $\mathrm{ABA}$ during germination and seedling establishment. Later in development, sca3 plants displayed reduced sensitivity to salt stress. A gene ontology (GO) analysis of the nuclear genes differentially expressed in the sca3-2 mutant (301) revealed that many significantly enriched GO terms were related to chloroplast function, and also to the response to several abiotic stresses. By quantitative RT-PCR (qRT-PCR), we found that genes LHCB1 (LIGHT-HARVESTING CHLOROPHYLL a/b-BINDING1) and AOX1A (ALTERNATIVE OXIDASE 1A) were respectively downand up-regulated in the Columbia-0 (Col-0) salt-stressed plants, which suggests the activation of plastid and mitochondria-to-nucleus retrograde signaling. The transcript levels of genes RPOTp, RPOTmp and RPOTm significantly increased in these salt-stressed seedlings, but this enhanced expression did not lead to the up-regulation of the plastid genes solely transcribed by NEP. Similar to salinity, carotenoid inhibitor norflurazon (NF) also enhanced the RPOTp transcript levels in Col-0 seedlings. This shows that besides salinity, inhibition of chloroplast biogenesis also induces RPOTp expression. Unlike salt and NF, the NEP genes were significantly down-regulated in the Col-0 seedlings grown in ABA-supplemented media. Together, our findings demonstrate that RPOTp functions in abiotic stress tolerance, and RPOTp is likely regulated positively by plastid-to-nucleus retrograde signaling, which is triggered when chloroplast functionality is perturbed by environmental stresses, e.g., salinity or NF. This suggests the existence of a compensatory mechanism, elicited by impaired chloroplast function. To our knowledge, this is the first study to suggest the role of a nuclear-encoded plastid-RNA polymerase in salt stress tolerance in plants.
\end{abstract}

Keywords: Arabidopsis; RPOTp; salt stress; abiotic stress; plastid gene expression; abscisic acid 


\section{Introduction}

The hypothesis that chloroplasts descend by endosymbiosis from erstwhile free-living, photosynthetically active cyanobacteria is currently widely accepted by the scientific community [1]. Nearly all the genes of the initially genetically autonomous endosymbiont were lost or relocated to the nucleus of the host cell. As a result, its activity was finally dependent on the functions provided by the host [2]. However, the endosymbiont retained part of the ancestral DNA, which eventually gave rise to the genomes of the different types of currently-existing plastids, including chloroplasts. Compared to the ancestral cyanobacteria from which they evolved, chloroplasts contain a very small genome (plastome) that typically ranges from 120 to $160 \mathrm{~kb}$ in size, and harbors only 90 to 100 genes, mostly involved in photosynthesis and plastid gene expression (PGE; [3]). PGE regulation can occur via the modulation of the number of copies of the plastome, or through mechanisms of transcriptional, post-transcriptional, translational or post-translational control [4].

The transcriptional control of PGE is highly complex. Along this line, the transcriptional machinery of the chloroplasts of land plants is more complex than that of prokaryotes. Accordingly, plastid genes are transcribed by two types of DNA-dependent RNA polymerases: PEP (Plastid-Encoded Polymerase), a bacterial-type polymerase encoded by the plastome, and NEP (Nuclear-Encoded Polymerase), a monomeric-type polymerase similar to that of T3/T7 phages, encoded by the nuclear genome [4]. PEP is a multimeric enzyme composed of subunits $\alpha, \beta, \beta^{\prime}$ and $\beta^{\prime \prime}$, which form the core of the enzyme (holoenzyme), and which are respectively encoded by plastome genes rpoA, rpoB, rpoC1 and rpoC2 [5-7]. When isolated from photosynthetically active plastids, the PEP holoenzyme is usually associated with several nuclear-encoded proteins, such as sigma factors (SIG), which confer promoter recognition, and the PEP-associated proteins (PAP) required for plastid transcriptional regulation [8-11]. In addition to PEP, the second level of the control of chloroplast transcription in land plants is represented by NEP polymerases. In monocots, a single NEP coded by the RPOTp gene (RNA polymerase T3/T7 phage-type) has been hitherto identified, whereas two NEPs are present in dicots: RPOTp, targeted to plastids, and RPOTmp, dually targeted to plastids and mitochondria [12-15]. Plastid RPOTp and RPOTmp polymerases most likely evolved from the duplication of an ancestral-nuclear gene encoding mitochondrial RPOTm polymerase [16]. Along these lines, the small RPOT gene family in Arabidopsis comprises three members, that encode mitochondrial- (RPOTm), chloroplast- (RPOTp) and both organelle-targeted (RPOTmp) polymerases [12-14].

In stark contrast to PEP, NEP polymerases are single catalytic subunits that perform the entire transcription process, from promoter recognition to termination [17]. PEP is considered the predominant plant-RNA polymerase in green organs because it transcribes most plastid genes [18]. Notwithstanding, NEP remains essential for the expression of the chloroplast genes rpoB, rpoC1 and rpoC2 (which constitute an operon), and $r p o A$ and $a c c D$ (which encode the $\beta$ subunit of acetyl-CoA carboxylase for lipid biosynthesis), in dicots [4]. Despite the proposal that RPOTp and RPOTmp display their highest levels of activity in different tissues and/or developmental stages in dicots, very few data currently support a distribution of functions between both RNA polymerases. In line with this, Arabidopsis RPOTmp activity has been reported in the non-photosynthetically and actively dividing cells of different organs, while that of RPOTp has been detected mainly in cells of green tissues [19].

Plant mutant analysis suggests the fundamental role of both PEP and NEP in chloroplast transcription, and, hence, in this organelle's biogenesis and function. Along these lines, tobacco PEP-defective mutants are impaired in photosynthesis, and display an albino phenotype $[18,20,21]$. Knocking out Arabidopsis genes RPOTmp [22], and principally RPOTp, the latter in scabra3 (sca3) mutants [23], has resulted in abnormal chloroplast development, stunted growth, reduced pigmentation and altered leaf morphogenesis. Interestingly, the rрoTmp sca3-2 double mutant individuals exhibit a more severe phenotype, and even arrest growth early in development [23].

Chloroplasts may play a fundamental role in plant stress responses by sensing abiotic stress and transmitting this information to the nucleus, in order to coordinate the expression of nuclear and plastome genes. In this way, organelle activity adjusts to the new environmental conditions, 
which allows plants to cope with stress [24]. Accordingly, PGE has to adequately respond to changes in development, and also to environmental stimuli. Accordingly, it has recently been reported that a disruption of the function of genes involved in PGE alters a plant's response to abiotic stress [24,25]. In the last few years, several nuclear genes sensitive to salinity that encode plastid proteins have been described, and some are also involved in PGE regulation [26,27]. Besides, Arabidopsis mutants affected in nuclear genes required for PGE show altered responses to different abiotic stresses [24,25]. Notwithstanding, currently available information on the effects of altered PGE on plant stress tolerance is still limited.

To gain insight into the role of PGE in plant responses to abiotic stress, we decided to investigate whether NEP RPOTp could be involved in plant salt tolerance. Two strong loss-of-function mutant alleles of the RPOTp gene (sca3-2 and sca3-3) were morphologically and molecularly characterized in a previous work [23]. However, whether the SCA3 (RPOTp) gene plays a role in tolerance to abiotic stress remains to be assessed. We report herein a study of the sensitivity of sca3 mutants to not only ionic and osmotic stresses, but also to the abscisic acid (ABA) hormone involved in plant responses to stress. We performed an analysis of gene ontologies (GO) for the genes differentially expressed in the sca3-2 mutant, and investigated the effect of salt stress and ABA on the expression of NEP and plastome genes. We then examined RPOTp expression in response to carotenoid inhibitor norflurazon (NF). Our results reveal that RPOTp function, which is required for abiotic stress tolerance, is controlled by plastid-to-nucleus retrograde signaling, which is triggered when chloroplast functionality is perturbed by environmental stress. As far as we know, this is the first study to suggest a role for NEP in salt stress tolerance in plants.

\section{Results}

\subsection{Knock-Down of RPOTp Alters $\mathrm{NaCl}$, Mannitol and ABA Responses}

To determine if plastid RNA polymerase RPOTp could be involved in plants' tolerance to environmental stress, we studied the sensitivity of Arabidopsis wild-type Columbia-0 (Col-0) and T-DNA mutants sca3-2 and sca3-3 [23] to different abiotic stresses. To this end, Col-0 and sca3 mutant seeds were sown in a culture media supplemented with $150 \mathrm{mM} \mathrm{NaCl}$ or $350 \mathrm{mM}$ mannitol, which respectively cause ionic and osmotic stress, and their ability to germinate and to form fully expanded green cotyledons (seedling establishment) was examined for 14 DAS (days after stratification).

In the absence of stress, the sca3 mutant seeds yielded similar germination values to those of the wild-type seeds, although the sca3-2 mutant showed slightly lower values than Col-0 during the first culture week (Figure 1a). NaCl or mannitol exogenously applied to the growth medium delayed Col-0 and sca3 germination, although this effect was much more pronounced in both mutants, particularly in sca3-2 (Figure 1c). In response to mannitol, the germination differences between Col-0 and the sca3 mutants became even more evident, and the sca3-2 mutant was more sensitive than sca3-3 (Figure 1e).

Seedling establishment was delayed in the sca3 mutants compared to Col-0 for the first 7 DAS in the MS control medium (Figure 1b). This is consistent with the defective photoautotrophic growth previously reported for these mutants [23]. The differences between Col-0 and the sca3 mutants were substantially marked in the presence of $150 \mathrm{mM} \mathrm{NaCl}$ or $350 \mathrm{mM}$ mannitol, and sca3-2 was more sensitive than sca3-3 (Figure 1d,f). In line with this, at 10 DAS, 95\%, 42\% and 25\% seedling establishment was achieved for the Col-0, sca3-3 and sca3-2 mutant seeds, respectively, with $150 \mathrm{mM}$ of $\mathrm{NaCl}$ (Figure 1d). Furthermore, at 14 DAS in the presence of mannitol, $90 \%$ of the Col-0 seeds yielded seedlings with green expanded cotyledons, as opposed to only $15 \%$ and $23 \%$ of sca3-2 and sca3-3, respectively (Figure 1f). 


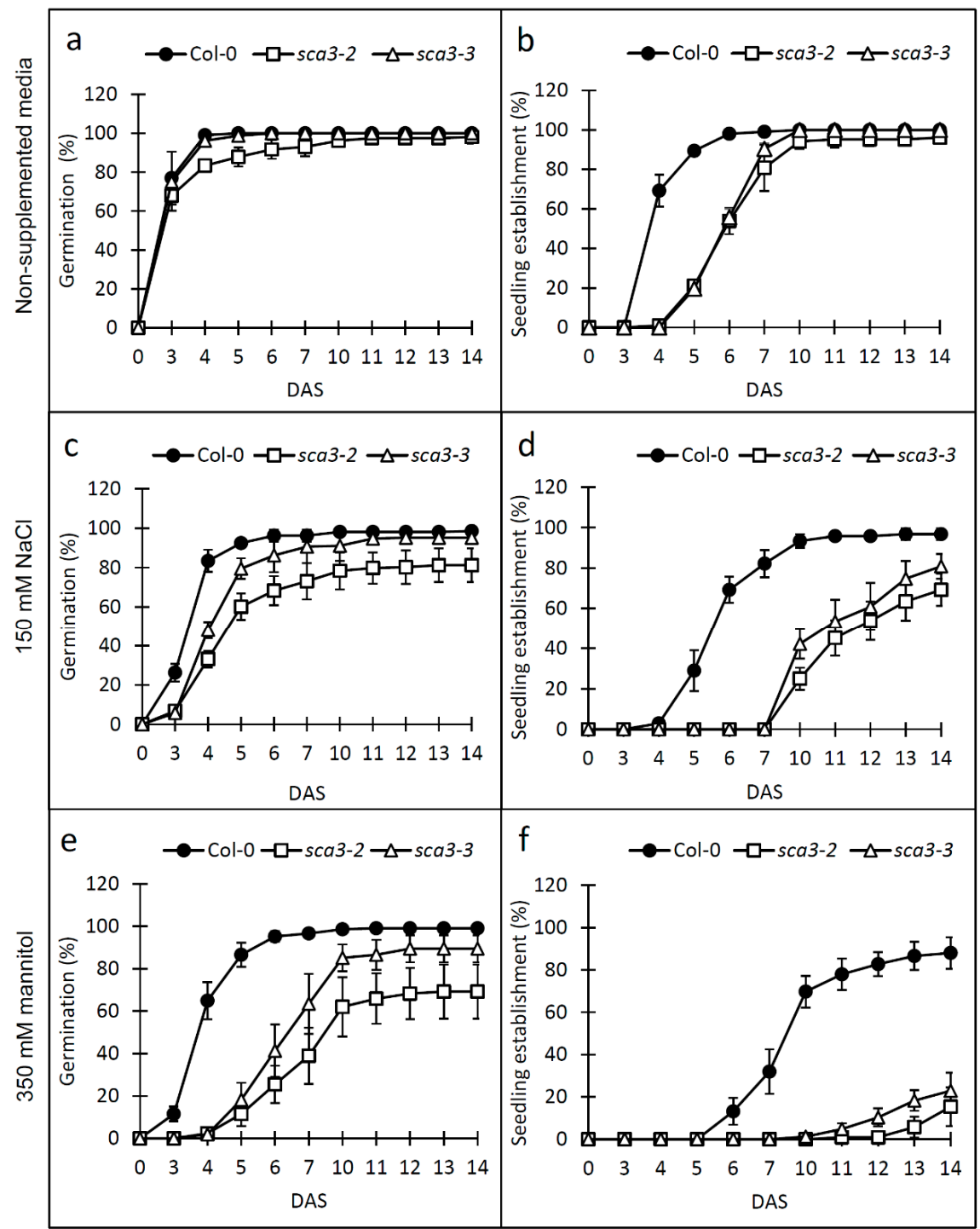

Figure 1. Effects of $\mathrm{NaCl}$ and mannitol on germination and seedling establishment in the wild-type Col-0 and mutants sca3-2 and sca3-3. Each value corresponds to the mean \pm standard deviation (SD) of the percentage of germination $(\mathbf{a}, \mathbf{c}, \mathbf{e})$ and seedling establishment $(\mathbf{b}, \mathbf{d}, \mathbf{f})$ in growth media, either without supplementation (a,b), or supplemented with $150 \mathrm{mM} \mathrm{NaCl}(\mathbf{c}, \mathbf{d})$ or $350 \mathrm{mM}$ mannitol (e,f), for four replicates of at least 50 seeds each per genotype. DAS: days after stratification.

The ABA hormone is induced in response to abiotic stress, and plays a fundamental role in adapting plants to adverse environmental conditions [28]. Mutants displaying altered sensitivity to abiotic stress frequently exhibit abnormal responses to ABA [25]. The enhanced sensitivity of the sca3 mutants to $\mathrm{NaCl}$ and mannitol prompted us to investigate their response to $\mathrm{ABA}$. To do so, the sca3 and Col-0 seeds were sown in the MS growth media supplemented with 1.5 or $3 \mu \mathrm{M}$ ABA. Germination of the sca3 mutants was more sensitive to ABA than that of Col-0, especially sca3-2 in the presence of $3 \mu \mathrm{M}$ ABA (Figure 2a,b), which is similar to the results obtained with salt or mannitol stress (Figure 1). These differences were more marked from 6 to 10 DAS (Figure 2a,c,e). The ABA concentrations led to a noticeable reduction in seedling establishment in the Col-0 and sca3 mutants throughout the study period, although the mutants were more sensitive than Col-0. Accordingly, at 14 DAS, $73 \%$ of the Col- 0 seeds, and $30 \%$ and $37 \%$ of the sca3-2 and sca3-3 seeds, respectively, yielded seedlings with green expanded cotyledons, with $1.5 \mu \mathrm{M}$ ABA (Figure 2d). These percentages lowered to $48 \%, 12 \%$ and $24 \%$ for Col-0, sca3-2 and sca3-3, respectively, with $3 \mu \mathrm{M}$ ABA (Figure 2f). 


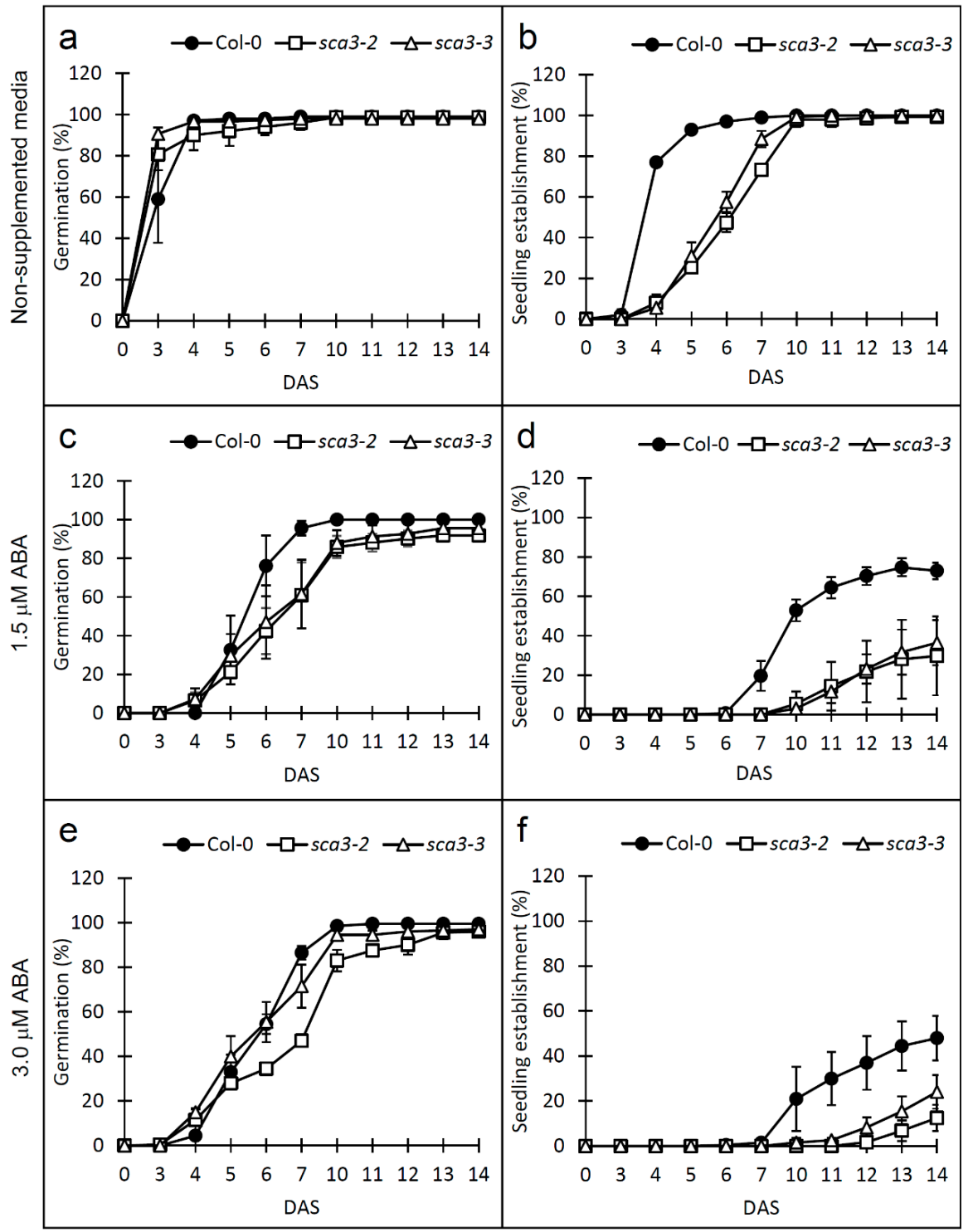

Figure 2. Effects of ABA on germination and seedling establishment in the wild-type Col-0 and mutants sca3-2 and sca3-3. Each value corresponds to the mean \pm standard deviation (SD) of the percentage of germination $(\mathbf{a}, \mathbf{c}, \mathbf{e})$ and seedling establishment $(\mathbf{b}, \mathbf{d}, \mathbf{f})$ in growth media, either without supplementation $(\mathbf{a}, \mathbf{b})$, or supplemented with $1.5 \mu \mathrm{M}$ ABA $(\mathbf{c}, \mathbf{d})$ or $3 \mu \mathrm{M}$ ABA $(\mathbf{e}, \mathbf{f})$, for four replicates of at least 50 seeds each per genotype.

To confirm the role of RPOTp in abiotic stress tolerance, we also calculated, from 0 to 14 DAS, the Col-0/sca3-2 and Col-0/sca3-3 ratios for both percentages of germination and seedling establishment, under control conditions and in response to $150 \mathrm{mM} \mathrm{NaCl}, 350 \mathrm{mM}$ mannitol, or 1.5 or $3 \mu \mathrm{M}$ ABA (Table S1). In non-supplemented growth media, the Col-0/sca3-2 and Col-0/sca3-3 values were very similar (usually 1 , or very close to 1 ). In the presence of $\mathrm{NaCl}$, mannitol or $\mathrm{ABA}$, the Col-0/sca3 ratios for germination and seedling establishment yielded higher values than they did in non-supplemented growth media, which is in line with the hypersensitivity of $s c a 3$ mutants to these stress conditions (Table S1; Figures 1 and 2). Interestingly, the Col-0/sca3-2 ratios were usually higher than those of Col-0/sca3-3, which is consistent with the enhanced sensitivity of sca3-2 to stress (Table S1).

Taken together, our results showed that the sca3 mutants were hypersensitive to not only ionic and osmotic stresses, but also to ABA during germination and seedling establishment, and sca3-2 was more sensitive than $s c a 3-3$. 
We also evaluated the response of the sca3 plants to salt and ABA later in development, without the detrimental effect that $\mathrm{NaCl}$ and $\mathrm{ABA}$ exert on germination and seedling establishment. To this end, Col-0 and mutant plants were transferred, at 7 DAS, from non-supplemented agar medium to MS-control media, or media supplemented with $\mathrm{NaCl}(125$ or $150 \mathrm{mM} \mathrm{NaCl})$ or ABA (5 or $10 \mu \mathrm{M})$. Root length was determined at 14 DAS (see Materials and Methods). The roots of the sca3 individuals were significantly shorter than those of the Col-0, in the MS-control medium or in the presence of $\mathrm{NaCl}$ or ABA (Figure S1). With salt stress, the sca3 mutants were significantly less sensitive than Col-0 to the root growth inhibition caused by either $125 \mathrm{mM}$ or $150 \mathrm{mM} \mathrm{NaCl}$ (Figure 3a). With the ABA-supplemented media, no significant differences in root length inhibition were found between the sca3 and Col-0 plants, except for the sca3-3 mutant in response to $10 \mu \mathrm{M}$ ABA, which was slightly more sensitive than Col-0 (Figure 3b).

\section{a}

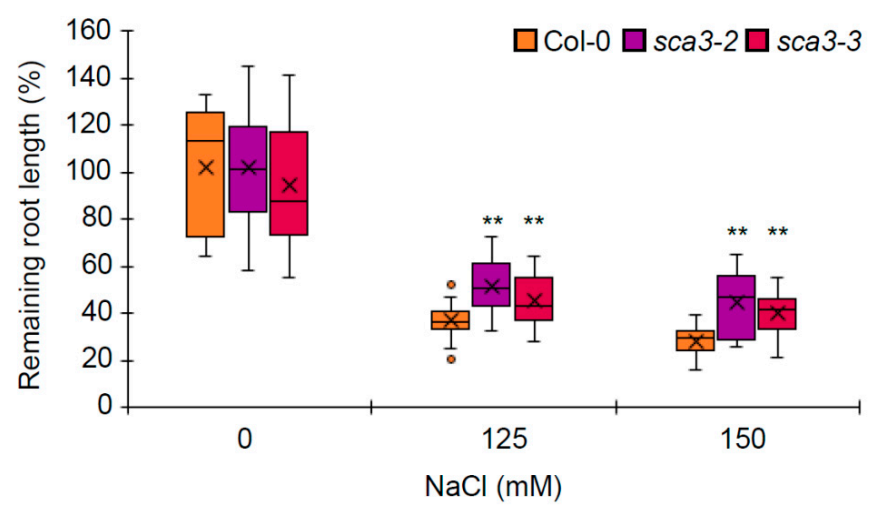

b

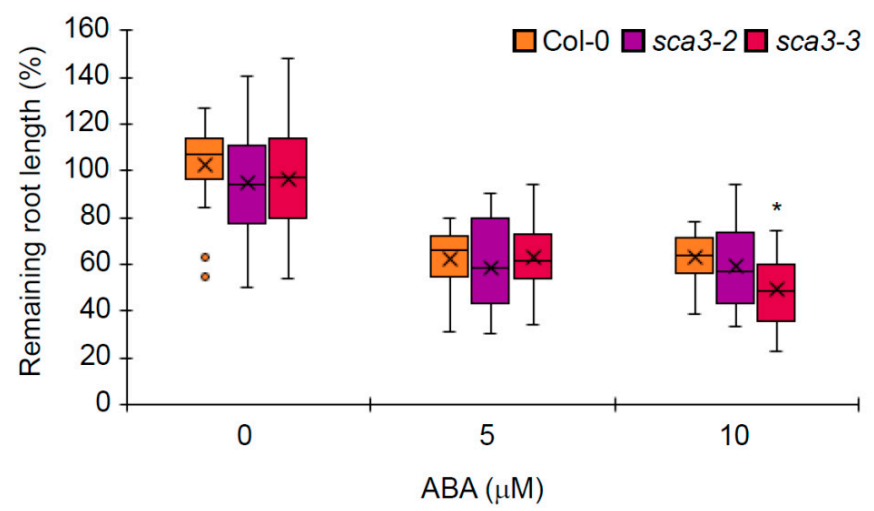

Figure 3. Box plots for sensitivity to $\mathrm{ABA}$ and $\mathrm{NaCl}$ of sca3 plants. Individuals were transplanted at 7 DAS from the non-supplemented growth media to the media supplemented with either 125 or $150 \mathrm{mM}$ $\mathrm{NaCl}$, or 5 or $10 \mu \mathrm{M}$ ABA. Seven days after the transfer, the root lengths of the plants transferred to the NaCl- (a) or ABA- (b) supplemented media were determined and referred to those of the same genotypes transferred to the non-supplemented media. These values are represented as percentages of root length of the plants transferred to the non-supplemented media. Dark horizontal lines represent the median, $(x)$ denotes the mean, the box represents the 25th and 75th percentiles, whiskers represent the 1.5 IQR (Inter-Quartile Range) limits and outliers are shown by dots $(n \geq 15)$. Values significantly differed from Col- 0 at $* p<0.05$ or ${ }^{* *} p<0.01$, according to a Student's t-test.

\subsection{Analysis of Gene Ontologies in the Transcriptome of the sca3-2 Mutant}

A microarray analysis of the transcriptome of the sca3-2 mutant, previously performed using total RNA extracted from 3-week-old plants, revealed 301 differentially expressed (DE) nuclear genes, 198 and 103 down- and up-regulated, respectively, compared to Col-0 [23]. No organellar genes were 
present in the array. We decided to examine the set of DE in sca3-2 to identify functions related to abiotic stress response. To this end, we carried out an analysis of gene ontologies (GO) using the Singular Enrichment Analysis (SEA) online tool, accessed through agriGO v2.0 [29]. This allowed us to find which GO terms are enriched, that is, over-represented (or under-represented), using annotations for a given gene set. Enriched GO terms appear, statistically, more (or less) frequently than would be expected just by chance when analyzing the list of annotated terms for the set of input genes.

We performed the GO enrichment analysis on the sets of 198 under-expressed and 103 over-expressed genes separately. For the under-expressed genes, we found 95 terms significantly enriched (all of them over-represented), of which 48, 38 and 9 terms belonged to the 'biological process', 'cellular component' and 'molecular function' sub-ontologies, respectively (Table S2). Interestingly, we identified numerous GO terms that were associated with environmental stress, and which were significantly enriched in the set of under-expressed genes in the sca3-2 mutant. The most significantly enriched term in the 'biological process' was 'response to a low light intensity stimulus' (GO:0009645), as $26.35 \%$ of the genes containing this term in the background set of genes were DE in sca3-2 (Table S2). Interestingly, most of the identified terms in this sub-ontology were associated with the response to external stimuli, with different types of stresses: 'response to water deprivation' (GO:0009414), 'response to oxidative stress' (GO:0006979), 'response to abiotic stimulus' (GO:0009628), 'response to cold' (GO:0009409), 'response to osmotic stress' (GO:0006970) or 'response to stress' (GO:0006950). Another group of terms significantly enriched in this ontology were those related to photosynthesis, such as 'photosynthesis, light harvesting' (GO:0009765), 'photorespiration' (GO:0009853) or 'photosynthesis, light reaction' (GO:0019684) (Table S2). For the 'molecular function' sub-ontology, the most significantly enriched term was 'pigment binding' (GO:0031409), as 22.72\% of the genes in the background set of genes containing this term were DE in sca3-2. Consistent with this, other significantly enriched terms were 'chlorophyll binding' (GO:0016168), 'tetrapyrrole binding' (GO:0046906) and 'catalytic activity' (GO:0003824) (Table S2). Finally, in relation to the 'cellular component' sub-ontology, it is worth noting the significantly enriched GO terms related to chloroplasts, and particularly to the thylakoid, which fell in line with the terms found in the other two sub-ontologies: 'photosystem I' (GO:0009522), 'plastoglobule' (GO:0010287), 'chloroplast thylakoid membrane protein complex' (GO:0098807), 'thylakoid lumen' (GO:0031977), 'chloroplast thylakoid' (GO:0009534), 'organelle subcompartment' (GO:0031984) or 'plastid stroma' (GO:0009532). 'Light-harvesting complex' (GO:0030076) was the most significantly enriched term $(20 \%$ of all the genes containing this term in the background set of genes were under-expressed in sca3-2) (Table S2).

As regards the over-expressed genes, we found only eight terms significantly enriched, all of them over-represented and belonging to the 'cellular component' sub-ontology, but none of them related to the terms identified from the under-expressed genes (Table S2).

Together, these results indicate that many sca3-2 down-regulated genes were involved in either photosynthesis or abiotic stress responses. Consequently, the diminished activity of these genes in this mutant could account for sca3-defective photoautotrophic growth [23] and the altered sensitivity to stress.

\subsection{RPOTp Expression is Controlled by Plastid Retrograde Signaling in Response to Salt Stress}

To gain further insight into the role of PGE in plant responses to abiotic stress, more specifically to salinity, we decided to investigate the effect that salt stress could have on the steady-state levels of the transcripts of the three Arabidopsis NEP genes: RPOTp, RPOTmp and RPOTm. We decided to perform this analysis on the Col-0 seedlings grown under similar conditions to those we previously assayed (see Figure 1, and Materials and Methods). To this end, Col-0 seedlings were grown in medium supplemented, or not, with $100 \mathrm{mM} \mathrm{NaCl}$. This condition significantly delayed seedling growth, but did not impair growth as severely as $150 \mathrm{mM} \mathrm{NaCl}$ (the concentration we used in the germination and seedling establishment assays) (Figure 1). At 10 DAS, total RNA was extracted and retro-transcribed, and cDNAs were analyzed by quantitative PCR (qPCR). To confirm the effectiveness of the salt stress 
treatment, we first studied the expression of the RD29A (RESPONSIVE TO DESICCATION 29A) and COR15B (COLD-REGULATED 15B) genes, which are induced by exposure to salinity, cold or ABA [30]. As expected for salt stress, the transcript levels of $R D 29 A$ and COR15B significantly increased in the Col-0 seedlings grown on $100 \mathrm{mM} \mathrm{NaCl}$ (4.8- and 2.7-fold up-regulated, respectively; Table 1). As regards the expression of the NEP genes, the treatment with $100 \mathrm{mM} \mathrm{NaCl}$ led to a significant increase in the steady-state levels of the transcripts of them all, albeit to different extents. Accordingly, RPOTm, RPOTp and RPOTmp were 1.3-, 2.3- and 3.5-fold up-regulated, respectively (Table 1). To determine the specificity of the effect of salt stress on the expression of the NEP genes, we studied the transcript levels of two nuclear genes that encode chloroplast-targeted proteins also involved in PGE: the mitochondrial transcription termination factors mTERF5 and mTERF9. These mTERFs are functionally related to RPOTp and are required for chloroplast development and response to abiotic stress [31]; furthermore, mTERF5 regulates transcription of the plastid psbEFLJ polycistron [32]. In stark contrast to the NEP genes, we found that $100 \mathrm{mM}$ of $\mathrm{NaCl}$ significantly repressed mTERF5 expression (1.3-fold down-regulated) and did not noticeably modify mTERF9 transcript abundance (Table 1).

Table 1. Quantitative RT-PCR analysis of the expression of chloroplast and nuclear genes in Col-0 seedlings exposed to $100 \mathrm{mM} \mathrm{NaCl}$.

\begin{tabular}{|c|c|c|c|}
\hline \multirow{2}{*}{ Gene } & \multicolumn{3}{|c|}{ Normalized Transcript Levels in Col-0 Plants Exposed to $100 \mathrm{mM} \mathrm{NaCl}$ Relative to Control Plants } \\
\hline & Protein Product & Fold Change & $p$-Value \\
\hline \multicolumn{4}{|l|}{ Nuclear genes } \\
\hline RPOTp/SCA3 & NEP ${ }^{1}$ RPOTp & $2.27 \pm 0.84$ & $4.113 \times 10^{-5 * *}$ \\
\hline RPOTmp & $\mathrm{NEP}^{1}$ RPOTmp & $3.50 \pm 1.70$ & $3.996 \times 10^{-4 * *}$ \\
\hline RPOTm & $\mathrm{NEP}^{1}$ RPOTm & $1.34 \pm 0.33$ & 0.036 * \\
\hline$A O X 1 A$ & Alternative oxidase $1 \mathrm{~A}$ & $3.90 \pm 1.00$ & $4.113 \times 10^{-5 * *}$ \\
\hline LHCB1 & Light-harvesting complex protein B1 & $0.70 \pm 0.44$ & $0.036^{*}$ \\
\hline mTERF5 & mTERF5 & $0.77 \pm 0.31$ & $0.008^{* *}$ \\
\hline mTERF9 & mTERF9 & $1.10 \pm 0.30$ & $0.015^{*}$ \\
\hline COR15B & Cold-regulated 15B & $4.76 \pm 2.11$ & $2.20 \times 10^{-10 * *}$ \\
\hline$R D 29 A$ & Responsive to desiccation $29 \mathrm{~A}$ & $2.74 \pm 0.76$ & $5.83 \times 10^{-4 * *}$ \\
\hline \multicolumn{4}{|l|}{ Chloroplast genes } \\
\hline psaA & Photosystem I reaction center protein & $1.12 \pm 0.49$ & 0.709 \\
\hline$p s a B$ & Photosystem I reaction center protein & $1.04 \pm 0.28$ & 0.709 \\
\hline$p s b A$ & Chlorophyll binding protein D1 & $0.60 \pm 0.22$ & $4.113 \times 10^{-5 * *}$ \\
\hline $\operatorname{clp} P$ & ATP-dependent protease & $1.18 \pm 0.27$ & $0.036^{*}$ \\
\hline rps18 & Ribosomal protein S18 & $0.83 \pm 0.23$ & 0.709 \\
\hline rроA & $\mathrm{PEP}^{2} \alpha$ subunit & $0.63 \pm 0.27$ & $0.001 * *$ \\
\hline rров & $\mathrm{PEP}^{2} \beta$ subunit & $0.61 \pm 0.09$ & $0.002 * *$ \\
\hline rpoc1 & $\mathrm{PEP}^{2} \beta^{\prime}$ subunit & $0.86 \pm 0.20$ & 0.220 \\
\hline$a c c D$ & $\begin{array}{c}\text { Carboxytransferase } \beta \text { subunit of the } \\
\text { Acetyl-CoA carboxylase }\end{array}$ & $0.88 \pm 0.35$ & 0.709 \\
\hline
\end{tabular}

\footnotetext{
${ }^{1}$ NEP: nuclear-encoded plastid RNA polymerase. ${ }^{2}$ PEP: plastid-encoded RNA polymerase. Relative expression values were determined as $2^{-\Delta \Delta C T}$ for each studied gene in 10 DAS Col-0 seedlings exposed to $100 \mathrm{mM}$ after normalization with those of the ACTIN2 gene, and compared with those of the Col-0 seedlings in control medium, to which a value of 1 was given (see Materials and Methods). Each value corresponds to the mean \pm standard deviation of the $2^{-\Delta \Delta C T}$ values obtained using three different biological replicates and triplicate reactions. Values were significantly different from the corresponding wild type at $p<0.05\left(^{*}\right)$ or $p<0.01\left(^{* *}\right)$ using Wilcoxon-Mann-Whitney test.
}

Together, our results reveal that salinity differentially affected the expression of nuclear genes involved in chloroplast transcription. To investigate if these changes in gene activity could result from retrograde signaling from chloroplasts to the nucleus, we decided to study, in the salt-stressed and non-salt stressed control Col-0 seedlings, the mRNA abundance of two marker genes for the activation of retrograde signaling from the chloroplast and mitochondria to the nucleus. To this end, the expression of the photosynthesis gene LHCB1 (encoding the LIGHT-HARVESTING CHLOROPHYLL a/b-BINDING1 protein) and the $A O X 1 A$ gene (encoding ALTERNATIVE OXIDASE 1A) were analyzed by qRT-PCR. It is well-known that the $L H C B 1$ gene is down-regulated when chloroplast biogenesis is perturbed [33], whereas $A O X 1 A$ expression increases in response to impaired mitochondria function, in order to protect plants from oxidative damage and prevent reactive oxygen species (ROS) production [34,35]. Compared to the non-stressed seedlings, accumulation of the LHCB1 transcripts significantly decreased 
(1.4-fold down-regulated), whereas $A O X 1 A$ mRNAs markedly increased (3.9-fold up-regulated), in the seedlings exposed to $100 \mathrm{mM} \mathrm{NaCl}$ (Table 1). Therefore, these results indicated that our salt stress conditions could trigger organelle retrograde signaling, which would, in turn, modulate the expression of NEP genes.

To study the regulation of NEP function by impaired chloroplast biogenesis in-depth, we analyzed the expression of the RPOTp gene in Col-0 seedlings grown in the presence or absence of NF, a bleaching herbicide that inhibits carotenoid biosynthesis and, consequently, chloroplast functionality [36]. When seedlings are treated with NF, the expression of photosynthesis-associated nuclear genes (such as LHCB1) is repressed, which has been interpreted as a result of plastid-to-nucleus retrograde signaling [37-39]. In our study, we included the gun1-1 mutant defective in the GUN1 protein, a central integrator of plastid retrograde signals [40]. Compared to the Col-0 seedlings grown on the control media, the presence of NF significantly increased RPOTp transcript abundance (2.4-fold up-regulated) (Figure 4), which was similar to $100 \mathrm{mM} \mathrm{NaCl}$. In the absence of NF, RPOTp expression in the gun1-1 mutant was significantly higher than in Col-0 (1.5-fold up-regulated) (Figure 4). This result is similar to the up-regulation of photosynthesis genes previously reported in this mutant [25,33]. Along these lines, the accumulation of RPOTp transcripts in the gun1-1 seedlings was higher than in Col-0 (1.6-fold up-regulated) when both strains were exposed to NF (Figure 4).

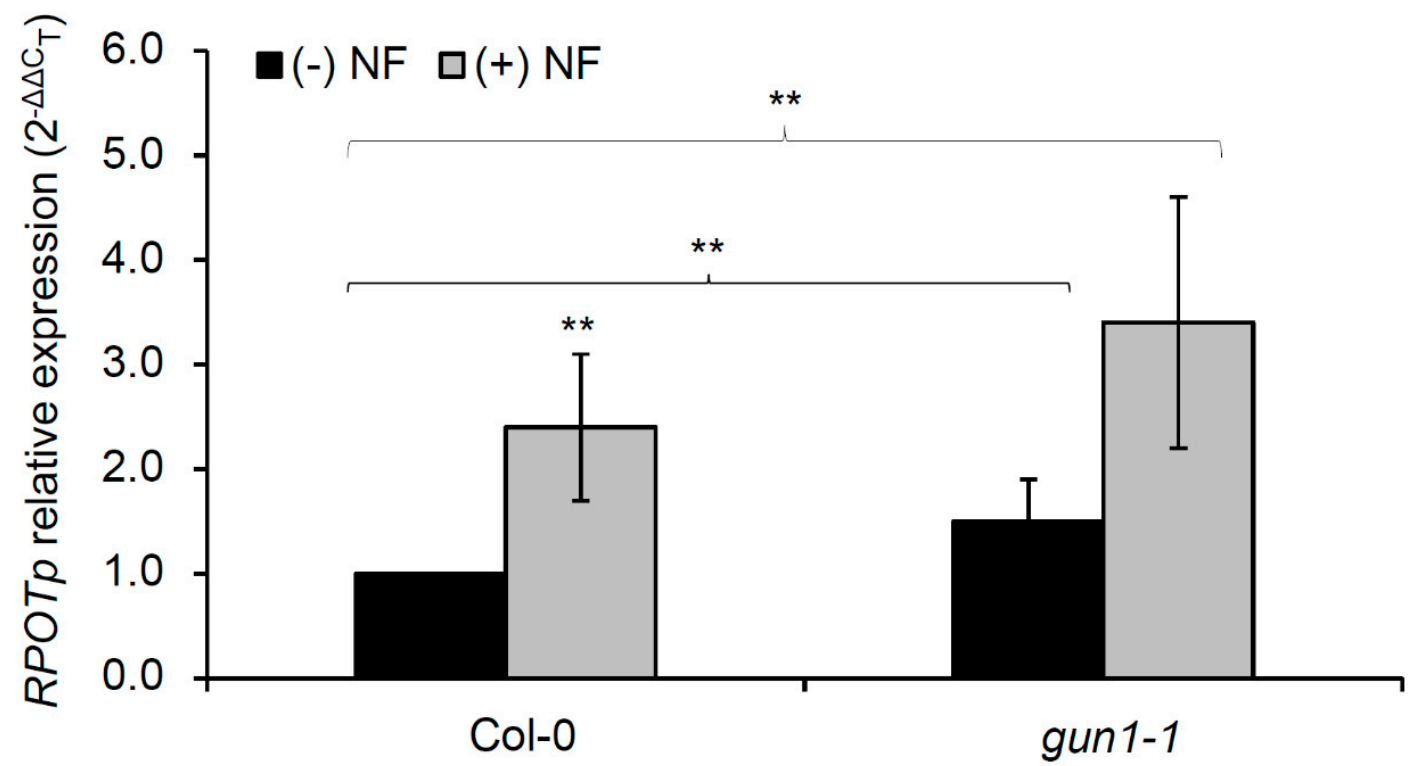

Figure 4. Analysis by qRT-PCR of RPOTp gene expression in Col-0 and the gun1-1 mutant in response to norflurazon (NF). RPOTp expression in Col-0 and the gun1-1 mutant in growth media supplemented $(+)$ or not $(-)$ with NF. Relative values were determined by the $2^{-\triangle \Delta C T}$ method for the RPOTp gene after normalization with those of the ACTIN2 gene, and compared to those of Col-0 in the non-supplemented media, to which a value of 1 was assigned. Each value corresponds to the mean \pm SD of three biological replicates and triplicate reactions. Asterisks indicate significant differences using a Mann-Whitney U-test $\left({ }^{* *} p<0.01\right)$ in the supplemented vs. non-supplemented media for each genotype. Plants were collected at 6 DAS.

Therefore, we conclude that applying NF or salt stress similarly increased RPOTp expression in the wild-type seedlings, and revealed a positive regulation of RPOTp transcript levels by retrograde signaling when chloroplast function is perturbed due to adverse environmental conditions.

\subsection{Salt Stress Differentially Affects the Transcript Abundance of Plastid-Encoded Genes}

To investigate the effect of salinity on the expression of the plastome, we studied, in Col-0 salt-stressed and non-stressed seedlings, the steady-state levels of the transcripts of the functionally 
different plastid genes transcribed by PEP or NEP RNA polymerases (Table 1). The selected genes encode proteins involved in photosynthesis ( $p s a A, p s a B$ and $p s b A$ encode Photosystem I and II reaction center proteins, respectively), protein degradation ( $c l p P$ encodes an ATP-dependent protease), translation (rps18 encodes ribosomal protein S18), lipid biosynthesis ( $a c c D$ encodes the Carboxyltransferase $\beta$ subunit of Acetyl-CoA carboxylase) and transcription ( $r p o A, r p o B$ and $r p o C 1$ encode the $\alpha, \beta$ and $\beta^{\prime}$ subunits of PEP, respectively) (Table 1). Compared to the non-stressed seedlings, the presence of $100 \mathrm{mM} \mathrm{NaCl}$ lowered the transcript levels of the majority of the studied genes (Table 1). This reduction was statistically significant for the $p s b A, r p o A$ and $r p o B$ genes (1.7-, 1.6- and 1.6-fold down-regulated, respectively), whereas no significant changes in transcript abundance were found for the remaining genes, except for $c l p P$, which was slightly up-regulated (Table 1). Consequently, although salt stress induced the expression of the RPOTp gene, this did not correlate with the mRNA levels of the plastid genes, which are fundamentally transcribed by RPOTp (rpoA, rpoB, rpoC1 and accD; Table 1).

\subsection{ABA Down-Regulates the Expression of NEP and Genes Encoding PEP Subunits}

ABA plays a pivotal role in the response of plants to different abiotic stresses [41]. Hence, we decided to investigate if the expression of NEP genes could also be affected by ABA. To this end, we determined by qRT-PCR the steady-state levels of the transcripts of the RPOTp, RPOTmp and RPOTm genes in 10 DAS Col-0 seedlings grown in the presence or absence of $1.5 \mu \mathrm{M}$ ABA. We included in this analysis the aforementioned nuclear genes $m$ TERF5 and $m$ TERF9, as well as plastid genes rpoA and $r p o B$, as representatives of genes essentially transcribed by NEP. We selected 1.5 $\mu \mathrm{M}$ ABA because this concentration slows and decreases Col-0 cotyledon greening, but to a lesser extent than $3 \mu \mathrm{M}$ ABA (Figure 2d,f), and it provided a sufficient number of seedlings to study the ABA effects at 10 DAS.

To confirm the effectiveness of the employed phytohormone concentration, we first analyzed the expression of the ABA-induced gene $R D 29 A$, as we did for $\mathrm{NaCl}$ stress (see above). In response to $1.5 \mu \mathrm{M}$ ABA, $R D 29 A$ was significantly up-regulated $\left(32.7 \pm 9.0 ; p=4.11 \times 10^{-4}\right)$, which was consistent with the induction of RD29A mRNA by ABA [30], and besides, it confirmed the effectiveness of our treatment. We found that ABA repressed the expression of all the studied genes, although this down-regulation was statistically significant for RPOTp $(0.62 \pm 0.21 ; p=0.001), \operatorname{mTERF5}(0.59 \pm 0.29$; $p=0.001)$, mTERF9 $\left(0.44 \pm 0.22 ; p=2.42 \times 10^{-6}\right), r p o A\left(0.52 \pm 0.18 ; p=4.113 \times 10^{-4}\right)$ and $r p o B(0.57 \pm 0.23$; $\left.p=4.113 \times 10^{-4}\right)$, but not for RPOTm $(0.85 \pm 0.32 ; p=0.223)$ or RPOTmp $(0.86 \pm 0.42 ; p=0.223)$.

\section{Discussion}

This work investigated the role of Arabidopsis plastid-RNA polymerase RPOTp in tolerance to abiotic stress. To this end, the germination and seedling establishment of strong loss-of-function mutants sca3-2 and sca3-3, affected in the RPOTp gene, were studied under different abiotic stress conditions. sca3 mutants were hypersensitive to $\mathrm{NaCl}$, mannitol and $\mathrm{ABA}$ during germination and seedling establishment, and sca3-2 was more sensitive to stress than sca3-3. This is consistent with the location of the T-DNA insertions in the RPOTp gene in these mutants (intron 3 and exon 18 in sca3-2 and sca3-3, respectively [23]). Along these lines, it has been reported that the sca3-2 mutant exhibits enhanced sensitivity to cold in the seedling stage [23]. We consider that the hypersensitivity to stress displayed by the sca3 mutants is due to impaired RPOTp function, and does not result from a delayed germination caused by the stress treatments. Consistent with this, other chloroplast-defective mutants, such as mterf9 [which also shows, like sca3 plants, stunted growth and impaired chloroplast biogenesis, and is morphologically very similar to sca3 (both mutations even interact synergistically)], display enhanced tolerance to abiotic stress [31,42]. As such, these results suggest that RPOTp promotes tolerance to environmental stress during germination and seedling establishment. Later in development, RPOTp would act differently, because the sca3-2 and sca3-3 roots were less sensitive than Col-0 to $\mathrm{NaCl}$. However, we cannot rule out that this deviating response to stress could be due to the different activities of RPOTp and RPOTmp in tissues and developmental stages [4], because RPOTmp and RPOTp expressions were detected mainly in the non-green cells of different organs and 
in photosynthetically active tissues, respectively [43]. Alternatively, the lesser reduction in root length of sca3 plants exposed to salt stress, compared to the wild-type, might result from the sca3-2 and sca3-3 roots being closer to a growth limit situation (Figure S1).

Altered sensitivity to salt stress has been reported for other Arabidopsis mutants defective in genes involved in PGE $[26,42,44,45]$. Noteworthy among these genes, $m$ TERF5, $m$ TERF6 and SIGMA FACTOR5 (SIG5) regulate chloroplast transcription. Accordingly, mTERF5 acts as a PEP transcriptional pausing factor that specifically modulates the transcription of plastid $p s b E F L J$ polycistron [32], whereas mTERF6 promotes the transcription termination of plastid $r p o A$ polycistron [46]. As for sca3 mutants, sig5-2 germination is hypersensitive to salinity, and SIG5 expression, unlike the remaining SIG genes, is induced in response to salinity and other abiotic stresses [47]. Nagashima et al. [47] suggested SIG5 is involved in protecting chloroplasts under abiotic stress by promoting the repair of the PSII reaction center. Recently, Zhao et al. [48] obtained transgenic lines overexpressing SIG5, which showed increased tolerance to salinity. As such, as these results show that both RPOTp- and PEP-mediated plastid transcription are involved in plant salt tolerance, we consider it feasible that PGE alteration at the transcriptional level may account for the abiotic stress phenotype of mutants sca3, mterf and sig5-2. Consistently with this, sca3-2 synergistically interacts with mutations mterf6-5 and mterf9 [31,49].

Our enrichment analysis of GO terms, which used the complete sets of under- and over-expressed genes in the sca3-2 mutant, revealed that most of the enriched GO terms belonged to the 'biological processes' and 'cellular components' sub-ontologies, and matched the expected function of RPOTp as a plastid-RNA polymerase. Accordingly, the GO terms related to photosynthesis or chloroplasts were significantly enriched in the set of down-regulated genes in sca3-2 plants. Besides, the GO terms associated with the response to different abiotic stresses were also significantly over-represented in this set of under-expressed genes, which falls in line with the stress phenotypes of the sca3-2 mutant. Consequently, the stress hypersensitivity of the sca3-2 mutant might be due to the down-regulation of these genes, at least in part.

Chloroplast genome expression is under dual genetic control, and changes in the activity of plastid-RNA polymerases, due to endogenous or external cues, can seriously affect chloroplast function. As such, we studied the effect of continuous exposure to moderate salt stress or ABA on the expression of NEP genes. Our results showed that the transcript levels of NEP genes significantly increased in response to salinity, albeit to different extents, because the mRNAs of genes RPOTmp and RPOTp respectively accumulated nearly three- and twofold more than those of RPOTm. In line with this, Danilova et al. [50] reported a higher level of expression of the RPOTmp vs. RPOTp genes under heat stress in Arabidopsis. Interestingly, NEP up-regulation by salt stress was not found in genes mTERF5 or $m T E R F 6$, which suggests a differential effect of salinity on the expression of the nuclear components of the plastid gene expression machinery. It is worth noting the enhanced expression of NEP genes in salt-stressed seedlings, which did not result in a significant up-regulation of plastid genes solely transcribed by NEP. This result somehow resembles the effect of heat stress on PEP and NEP expression, as reported by Danilova et al. [50]. These authors proposed heat stress causing PEP deficiency, which, in turn, would result in a compensatory increase in NEP expression at the mRNA level. Our findings fall in line with the activation of this compensatory mechanism—also in response to salinity-for maintaining chloroplast functionality. Along these lines, increased NEP transcript levels have been reported in mutants defective in PEP [21] or PAP [51] function. Reduced PEP activity by salt would account for the significant down-regulation of PEP-dependent PSII gene $p s b A$, but it did not noticeably affect the expression of genes PSI $p s a A$ and $p s a B$, also transcribed by PEP. A differential effect on the expression of plastid genes PSI and PSII has been reported in response to heat stress, which might be due to the different mechanisms governing the expression of these PS genes [50].

The effect of salinity on the accumulation and activity of NEP proteins remains to be elucidated. We have focused on the study of the steady-state levels of NEP mRNAs in response to salt stress. However, we cannot exclude that NEP up-regulation could be the consequence of impaired NEP activity by salinity, which still results in lower levels of NEP activity than under control conditions. 
As transcripts of RPOTm, which is solely targeted to mitochondria, also accumulated in response to $100 \mathrm{mM} \mathrm{NaCl}$, salinity also affected mitochondria activity. RPOTm up-regulation could be interpreted as an attempt to provide energy and to maintain metabolism under stress. Consistently with this, we found that the $A O X 1 A$ gene was overexpressed in salt-grown seedlings, which agrees with the reported activation of the AOX pathway in response to impaired mitochondrial function [34].

We found that all the NEP and PEP genes herein investigated were down-regulated by the externally applied ABA. Hence the lower transcript levels of the NEP-dependent-plastid genes could be due to the lowered RPOTp activity in response to ABA. The inhibitory effect of ABA on the expression of chloroplast and NEP genes has been previously described. Accordingly, Yamburenko et al. [52] reported that exogenously applied ABA represses Arabidopsis plastid transcription by both PEP and NEP. Besides, ABA also reduces RPOTp transcript accumulation to about $50 \%$ of the control levels, whereas those of RPOTmp remain unaffected [52]. The same authors obtained similar results in barley leaves [53]. In line with this, Danilova et al. [54] found that most of the nuclear genes that encode different plastid transcriptional machinery components, including RPOTp and RPOTmp, were down-regulated in Arabidopsis seedlings exposed to ABA. This repressive effect of ABA on plastid gene expression could be mediated by alarmone guanosine-30-50-bisdiphosphate (ppGpp), which accumulates in chloroplasts in response to abiotic stress, and to ABA, jasmonate or ethylene hormones [55,56]. ppGpp binds to the $\beta^{\prime}$-subunit of PEP, and inhibits the transcription that depends on this RNA polymerase. There is no evidence that ppGpp could repress RPOTp activity [56]. Therefore, RPOTp expression could be repressed by externally applying ABA through signaling to the nucleus, perhaps via PP2C and sucrose non fermenting protein-related kinases 2 (SnRK2) proteins, this being the pathway required for the expression of the enzymes that synthesize ppGpp [55]. Alternatively, RPOTp could be indirectly repressed by retrograde signal/s from chloroplasts to the nucleus, produced in response to ABA (e.g., ROS accumulating in response to reduced photosynthetic activity promoted by ABA [57]).

Our results show that the nuclear-photosynthesis gene $L H C B 1$, a classic marker of plastid retrograde signaling, was down-regulated in salt-grown Col-0 seedlings. This falls in line with the reduced expression of Arabidopsis nuclear-photosynthetic genes reported by Štefanic et al. [58] under similar stress conditions. Therefore, these findings indicate that salinity could activate chloroplast-to-nucleus signaling, and repress LHCB1, which occurs in response to chloroplast biogenesis inhibitor NF. Along these lines, we found that RPOTp transcripts accumulated when chloroplast biogenesis was blocked by NF. Thus changes in RPOTp gene expression under salt stress, like that of LHCB1, may also be due to plastid-to-nucleus retrograde signaling, but likely take place through an ABA-independent mechanism, because RPOTp expression was not induced by ABA. Accordingly, osmotic stress can alter nuclear transcription via ABA-independent signaling pathways [59].

The perturbation of chloroplast development by mutations can also increase RPOTp expression. Accordingly, genes RPOTp and RPOTm were overexpressed in the leaves of the albostrians mutant of barley that lacks chloroplast translation [19]. We previously reported RPOTp up-regulation in Arabidopsis mterf mutants defective in chloroplast development [42,49,60,61]. Furthermore, the results by Schweer et al. [62] suggest that NEP function might be reactivated when PEP activity is altered by mutations.

The results discussed herein point out the existence of a rescue or compensatory mechanism triggered by impaired chloroplast function, which would lead to enhanced NEP transcript levels. GUN1 might be an important component of the NEP-dependent compensatory mechanism, because Tadini et al. [63] recently found that GUN1 physically interacts with RPOTp and promotes its activity when PEP function is impaired. Our results, and those of Danilova et al. [50], suggest that such a mechanism would also act in wild-type plants to help them cope with adverse environmental stimuli, like salt and heat stress. Notwithstanding, further research is required to better understand the mechanisms involved in reprogramming nuclear and plastid gene expressions in order to adapt chloroplast function and plant activity to salinity and other abiotic stresses. 


\section{Materials and Methods}

\subsection{Plant Materials and Growth Conditions}

Plant cultures and crosses were carried out as reported in [61]. The seeds of Arabidopsis thaliana (L.) Heynh. wild-type accession Columbia-0 (Col-0) were obtained from the Nottingham Arabidopsis Stock Centre (NASC). The seeds of T-DNA insertional mutants sca3-2 and sca3-3 [23] and EMS-induced mutant gun1-1 [64], all in the Col-0 genetic background, have been previously described. The gun1-1 seeds were kindly provided by Dr. José Luis Micol.

\subsection{Germination and Growth Sensitivity Assays}

For the germination assays, sowings were performed as described in [61] on Petri dishes filled with GM agar medium [Murashige and Skoog (MS) medium containing 1\% sucrose], supplemented with $\mathrm{NaCl}(150 \mathrm{mM})$, mannitol $(350 \mathrm{mM})$ or ABA $(1.5$ or $3 \mu \mathrm{M})$. The seeds in which radicle emergence was observed were considered germinated, whereas seedling establishment was determined as the seedlings exhibiting green and fully expanded cotyledons. Seed germination and seedling establishment were scored from 1 to 14 DAS (days after stratification) on Petri dishes kept at $20 \pm 1^{\circ} \mathrm{C}$, with $25 \mu \mathrm{mol} \cdot \mathrm{m}^{-2} \cdot \mathrm{s}^{-1}$ of photons.

For the NF treatment, seedlings were grown on Petri dishes filled with GM agar medium supplemented with $5 \mu \mathrm{M}$ NF (Sigma-Aldrich, St. Louis, Missouri, USA).

To determine the salt and ABA responses during vegetative growth after seedling establishment, seeds were sown on non-supplemented GM agar medium, and seedlings were transferred at 7 DAS to new Petri dishes supplemented with $\mathrm{NaCl}(125$ or $150 \mathrm{mM})$ or $\mathrm{ABA}(5$ or $10 \mu \mathrm{M})$, and were vertically grown. Plant root length was determined after 7 days of $\mathrm{NaCl}$ or $\mathrm{ABA}$ treatment, to evaluate their tolerance to these stress conditions, by referring the values to those of the individuals transferred to the control (non-supplemented) media.

\subsection{Quantitative RT-PCR ( $q R T-P C R)$}

Total RNA was extracted from $80 \mathrm{mg}$ of wild-type Col-0 individuals at 6 and 10 DAS, and gun1-1 mutant seedlings at 6 DAS, which were grown on GM agar medium not supplemented or supplemented with $100 \mathrm{mM} \mathrm{NaCl}$ or $5 \mu \mathrm{M}$ NF. RNA was resuspended in $40 \mu \mathrm{L}$ of RNase-free water and DNA was removed with the TURBO DNAfree kit (Invitrogen, Carlsbad, California, USA) following the manufacturer's instructions. The cDNA preparations and qPCR amplifications were carried out in an ABI PRISM 7000 Sequence Detection System (Applied Biosystems, Foster City, California, USA) as described in [61] using the oligonucleotides listed in Table S1. Each reaction mix $(20 \mu \mathrm{L})$ contained $7.5 \mu \mathrm{L}$ of the SYBR-Green/ROX qPCR Master Kit (Fermentas, Vilnius, Lithuania), $0.4 \mu \mathrm{M}$ of primers and $1 \mu \mathrm{L}$ of cDNA solution. The relative quantification of gene expression data was performed by the $2^{-\Delta \Delta C T}$ or comparative $C_{t}$ method as reported in [65]. Each reaction was done in three replicates, and three different biological replicates were used. The expression levels were normalized to the CT values obtained for the housekeeping ACTIN2 gene [66].

\subsection{Statistical Analyses}

Statistical analyses were performed to compare, with the Col-0 non-stressed seedlings, the phenotypic traits and the relative transcript levels of the genes analyzed by qRT-PCR in the Col-0 seedlings treated with $100 \mathrm{mM} \mathrm{NaCl}, 1.5 \mu \mathrm{M}$ ABA or $5 \mu \mathrm{M}$ NF. Depending on the number of samples, a Mann-Whitney U-test $(\mathrm{n} \leq 10)$ or a Student's t-test $(\mathrm{n}>10)$ was applied.

\section{Conclusions}

The present study demonstrates the role of plastid-RNA polymerase RPOTp in plant salt tolerance. We draw this conclusion from the analysis of the stress phenotypes of RPOTp-deficient mutants, and by 
studying the expression of NEP and plastid genes in Col-0 seedlings exposed to salt stress, ABA or NF. Our findings also show that plastid-to-nucleus retrograde signaling modulates RPOTp transcript levels, which supports the existence of a transcriptional compensatory mechanism triggered by impaired chloroplast function upon abiotic stress.

Supplementary Materials: The following are available online at http://www.mdpi.com/2223-7747/9/7/834/s1, Table S1: Col-0/sca3 ratios of germination and seedling establishment values under control and stress conditions. Table S2: Analysis of gene ontologies (GO) in the nuclear transcriptome of mutant sca3-2. Table S3: Primers used in this work. Figure S1: Box plots for the root length of sca3 plants in response to ABA and NaCl. Individuals were transplanted at 7 DAS from the non-supplemented growth media to the media supplemented with either 125 or $150 \mathrm{mM} \mathrm{NaCl}$, or 5 or $10 \mu \mathrm{M}$ ABA. Seven days after transfer, the root lengths of the plants transferred to the $\mathrm{NaCl}-$ (A) or ABA- (B) supplemented media were determined. Dark horizontal lines represent the median, $(\times)$ denotes the mean, the box represents the 25th and 75th percentiles, whiskers represent the $1.5 \mathrm{IQR}$ limits and outliers are shown by dots $(n \geq 15)$. Values significantly differed from the Col- 0 at ${ }^{* *} p<0.01$ according to a Student's t-test.

Author Contributions: Conceptualization, V.Q.; Investigation, A.L.-S., E.N.-D., I.P.-M., P.R. and V.Q.; Resources, P.R. and V.Q.; Supervision, V.Q.; Writing: original draft, V.Q.; Writing: review and editing, E.N.-D., P.R. and V.Q. All authors have read and agreed to the published version of the manuscript.

Funding: This research received no external funding.

Conflicts of Interest: The authors have no conflicts of interest to declare.

\section{References}

1. Sagan, L. On the origin of mitosing cells. J. Theor. Biol. 1967, 14, 225-IN6. [CrossRef]

2. Bock, R.; Timmis, J.N. Reconstructing evolution: Gene transfer from plastids to the nucleus. Bioessays 2008, 30, 556-566. [CrossRef] [PubMed]

3. Wicke, S.; Schneeweiss, G.M.; dePamphilis, C.W.; Müller, K.F.; Quandt, D. The evolution of the plastid chromosome in land plants: Gene content, gene order, gene function. Plant Mol. Biol. 2011, 76, 273-297. [CrossRef]

4. Börner, T.; Aleynikova, A.Y.; Zubo, Y.O.; Kusnetsov, V.V. Chloroplast RNA polymerases: Role in chloroplast biogenesis. Biochim. Biophys. Acta 2015, 1847, 761-769. [CrossRef]

5. Ohyama, K.; Fukuzawa, H.; Kohchi, T.; Shirai, H.; Sano, T.; Sano, S.; Umesono, K.; Shiki, Y.; Takeuchi, M.; Chang, Z.; et al. Chloroplast gene organization deduced from complete sequence of liverwort Marchantia polymorpha chloroplast DNA. Nature 1986, 322, 572-574. [CrossRef]

6. Shinozaki, K.; Ohme, M.; Tanaka, M.; Wakasugi, T.; Hayashida, N.; Matsubayashi, T.; Zaita, N.; Chunwongse, J.; Obokata, J.; Yamaguchi-Shinozaki, K.; et al. The complete nucleotide sequence of the tobacco chloroplast genome: Its gene organization and expression. EMBO J. 1986, 5, 2043-2049. [CrossRef]

7. Sijben-Muller, G.; Hallick, R.B.; Alt, J.; Westhoff, P.; Herrmann, R.G. Spinach plastid genes coding for initiation factor IF-1, ribosomal protein S11 and RNA polymerase alpha-subunit. Nucleic Acids Res. 1986, 14, 1029-1044. [CrossRef] [PubMed]

8. Pfannschmidt, T.; Link, G. The A and B forms of plastid DNA-dependent RNA polymerase from mustard (Sinapis alba L.) transcribe the same genes in a different developmental context. Mol. Gen. Genet. 1997, 257, 35-44. [CrossRef] [PubMed]

9. Pfannschmidt, T.; Ogrzewalla, K.; Baginsky, S.; Sickmann, A.; Meyer, H.E.; Link, G. The multisubunit chloroplast RNA polymerase A from mustard (Sinapis alba L.). Integration of a prokaryotic core into a larger complex with organelle-specific functions. Eur. J. Biochem. 2000, 267, 253-261. [CrossRef] [PubMed]

10. Ogrzewalla, K.; Piotrowski, M.; Reinbothe, S.; Link, G. The plastid transcription kinase from mustard (Sinapis alba L.). A nuclear-encoded CK2-type chloroplast enzyme with redox-sensitive function. Eur. J. Biochem. 2002, 269, 3329-3337. [CrossRef]

11. Pfalz, J.; Liere, K.; Kandlbinder, A.; Dietz, K.J.; Oelmuller, R. pTAC2, -6, and -12 are components of the transcriptionally active plastid chromosome that are required for plastid gene expression. Plant. Cell 2006, 18, 176-197. [CrossRef] [PubMed]

12. Hedtke, B.; Börner, T.; Weihe, A. Mitochondrial and chloroplast phage-type RNA polymerases in Arabidopsis. Science 1997, 277, 809-811. [CrossRef]

13. Hedtke, B.; Wagner, I.; Börner, T.; Hess, W.R. Inter-organellar crosstalk in higher plants: Impaired chloroplast development affects mitochondrial gene and transcript levels. Plant J. 1999, 19, 635-643. [CrossRef] [PubMed] 
14. Hedtke, B.; Börner, T.; Weihe, A. One RNA polymerase serving two genomes. EMBO Rep. 2000, 1, 435-440. [CrossRef] [PubMed]

15. Kobayashi, Y.; Dokiya, Y.; Sugita, M. Dual targeting of phage-type RNA polymerase to both mitochondria and plastids is due to alternative translation initiation in single transcripts. Biochem. Biophys. Res. Commun. 2001, 289, 1106-1113. [CrossRef]

16. Liere, K.; Weihe, A.; Börner, T. The transcription machineries of plant mitochondria and chloroplasts: Composition, function, and regulation. J. Plant Physiol. 2011, 168, 1345-1360. [CrossRef]

17. Steitz, T.A. The structural changes of T7 RNA polymerase from transcription initiation to elongation. Curr. Opin. Struct. Biol. 2009, 19, 683-690. [CrossRef]

18. Hajdukiewicz, P.T.; Allison, L.A.; Maliga, P. The two RNA polymerases encoded by the nuclear and the plastid compartments transcribe distinct groups of genes in tobacco plastids. EMBO J. 1997, 16, 4041-4048. [CrossRef]

19. Emanuel, C.; Weihe, A.; Graner, A.; Hess, W.R.; Börner, T. Chloroplast development affects expression of phage-type RNA polymerases in barley leaves. Plant J. 2004, 38, 460-472. [CrossRef]

20. Allison, L.A.; Simon, L.D.; Maliga, P. Deletion of $r p o B$ reveals a second distinct transcription system in plastids of higher plants. EMBO J. 1996, 15, 2802-2809. [CrossRef]

21. Legen, J.; Kemp, S.; Krause, K.; Profanter, B.; Herrmann, R.G.; Maier, R.M. Comparative analysis of plastid transcription profiles of entire plastid chromosomes from tobacco attributed to wild-type and PEP-deficient transcription machineries. Plant J. 2002, 31, 171-188. [CrossRef] [PubMed]

22. Baba, K.; Schmidt, J.; Espinosa-Ruiz, A.; Villarejo, A.; Shiina, T.; Gardeström, P.; Sane, A.P.; Bhalerao, R.P. Organellar gene transcription and early seedling development are affected in the rpoT;2 mutant of Arabidopsis. Plant J. 2004, 38, 38-48. [CrossRef]

23. Hricová, A.; Quesada, V.; Micol, J.L. The SCABRA3 nuclear gene encodes the plastid RpoTp RNA polymerase, which is required for chloroplast biogenesis and mesophyll cell proliferation in Arabidopsis. Plant Physiol. 2006, 141, 942-956. [CrossRef] [PubMed]

24. Robles, P.; Quesada, V. Transcriptional and Post-transcriptional Regulation of Organellar Gene Expression (OGE) and Its Roles in Plant Salt Tolerance. Int. J. Mol. Sci. 2019, 20, 1056. [CrossRef] [PubMed]

25. Leister, D.; Wang, L.; Kleine, T. Organellar Gene Expression and Acclimation of Plants to Environmental Stress. Front. Plant Sci. 2017, 8, 387. [CrossRef] [PubMed]

26. Nawaz, G.; Kang, H. Chloroplast- or mitochondria-targeted DEAD-box RNA helicases play essential roles in organellar RNA metabolism and abiotic stress responses. Front. Plant Sci. 2017, 8, 871. [CrossRef]

27. Suo, J.; Zhao, Q.; David, L.; Chen, S.; Dai, S. Salinity Response in Chloroplasts: Insights from Gene Characterization. Int. J. Mol. Sci. 2017, 18, 1011. [CrossRef]

28. Danquah, A.; de Zelicourt, A.; Colcombet, J.; Hirt, H. The role of ABA and MAPK signaling pathways in plant abiotic stress responses. Biotechnol. Adv. 2014, 32, 40-52. [CrossRef]

29. Tian, T.; Liu, Y.; Heung, Y.; You, Q.; Yi, X.; Zhou, D.; Wenying, X.; Zhen, S. AgriGO v2.0: A GO analysis (toolkit for the agricultural community, 2017 update). Nucleic Acids Res. 2017, 45, W122-W129. [CrossRef]

30. Yamaguchi-Shinozaki, K.; Shinozaki, K. Characterization of the expression of a desiccation-responsive RD29 gene of Arabidopsis thaliana and analysis of its promoter in transgenic plants. Mol. Gen. Genet. 1993, 236, 331-340. [CrossRef]

31. Núñez-Delegido, E.; Robles, P.; Ferrández-Ayela, A.; Quesada, V. Functional analysis of mTERF5 and mTERF9 contribution to salt tolerance, plastid gene expression and retrograde signalling in Arabidopsis thaliana. Plant. Biol. 2020, 22, 459-471.

32. Ding, S.; Zhang, Y.; Hu, Z.; Huang, X.; Zhang, B.; Lu, Q.; Wen, X.; Wang, Y.; Lu, C. mTERF5 Acts as a Transcriptional Pausing Factor to Positively Regulate Transcription of Chloroplast psbEFLJ. Mol. Plant 2019, 12, 1259-1277. [CrossRef]

33. Sun, X.; Xu, D.; Liu, Z.; Kleine, T.; Leister, D. Functional relationship between mTERF4 and GUN1 in retrograde signalling. J. Exp. Bot. 2016, 67, 3909-3924. [CrossRef] [PubMed]

34. Giraud, E.; Van Aken, O.; Ho, L.H.; Whelan, J. The transcription factor ABI4 is a regulator of mitochondrial retrograde expression of ALTERNATIVE OXIDASE1a. Plant Physiol. 2009, 150, 1286-1296. [CrossRef] [PubMed]

35. Raghavendra, A.S.; Padmasree, K. Beneficial interactions of mitochondrial metabolism with photosynthetic carbon assimilation. Trends Plant Sci. 2003, 8, 546-553. [CrossRef] [PubMed] 
36. Susek, R.E.; Ausubel, F.M.; Chory, J. Signal transduction mutants of Arabidopsis uncouple nuclear CAB and RBCS gene expression from chloroplast development. Cell 1993, 74, 787-799. [CrossRef]

37. Leister, D. Genomics-based dissection of the cross-talk of chloroplasts with the nucleus and mitochondria in Arabidopsis. Gene 2005, 354, 110-116. [CrossRef] [PubMed]

38. Nott, A.; Jung, H.S.; Koussevitzky, S.; Chory, J. Plastid-to-nucleus retrograde signaling. Annu. Rev. Plant Biol. 2006, 57, 739-759. [CrossRef]

39. Kakizaki, T.; Matsumura, H.; Nakayama, K.; Che, F.S.; Terauchi, R.; Inaba, T. Coordination of plastid protein import and nuclear gene expression by plastid-to-nucleus retrograde signaling. Plant Physiol. 2009, 151, 1339-1353. [CrossRef]

40. Pesaresi, P.; Kim, C. Current understanding of GUN1: A key mediator involved in biogenic retrograde signaling. Plant Cell Rep. 2019, 38, 819-823. [CrossRef]

41. Zhu, J.K. Salt and drought stress signal transduction in plants. Annu. Rev. Plant Biol. 2002, 53, $247-273$. [CrossRef] [PubMed]

42. Robles, P.; Micol, J.L.; Quesada, V. Mutations in the plant-conserved MTERF9 alter chloroplast gene expression, development and tolerance to abiotic stress in Arabidopsis thaliana. Physiol. Plant 2015, 154, 297-313. [CrossRef]

43. Emanuel, C.; von Groll, U.; Müller, M.; Börner, T.; Weihe, A. Development- and tissue specific expression of the RpoT gene family of Arabidopsis encoding mitochondrial and plastid RNA polymerases. Planta 2006, 223, 998-1009. [CrossRef] [PubMed]

44. Robles, P.; Navarro-Cartagena, S.; Ferrández-Ayela, A.; Núñez-Delegido, E.; Quesada, V. The Characterization of Arabidopsis mterf6 Mutants Reveals a New Role for mTERF6 in Tolerance to Abiotic Stress. Int. J. Mol. Sci. 2018, 19, 2388. [CrossRef]

45. Romani, I.; Manavski, N.; Morosetti, A.; Tadini, L.; Maier, S.; Kühn, K.; Ruwe, H.; Schmitz-Linneweber, C.; Wanner, G.; Leister, D.; et al. A Member of the Arabidopsis Mitochondrial Transcription Termination Factor Family Is Required for Maturation of Chloroplast Transfer RNAIle (GAU). Plant Physiol. 2015, 169, 627-646. [CrossRef]

46. Zhang, Y.; Cui, Y.L.; Zhang, X.L.; Yu, Q.B.; Wang, X.; Yuan, X.B.; Qin, X.M.; He, X.F.; Huang, C.; Yang, Z.N. A nuclear-encoded protein, mTERF6, mediates transcription termination of rpoA polycistron for plastid-encoded RNA polymerase-dependent chloroplast gene expression and chloroplast development. Sci. Rep. 2018, 8, 11929. [CrossRef] [PubMed]

47. Nagashima, A.; Hanaoka, M.; Motohashi, R.; Seki, M.; Shinozaki, K.; Kanamaru, K.; Takahashi, H.; Tanaka, K. DNA microarray analysis of plastid gene expression in an Arabidopsis mutant deficient in a plastid transcription factor sigma, SIG2. Biosci. Biotechnol. Biochem. 2004, 68, 694-704. [CrossRef] [PubMed]

48. Zhao, P.; Cui, R.; Xu, P.; Wu, J.; Mao, J.L.; Chen, Y.; Zhou, C.Z.; Yu, L.H.; Xiang, C.B. ATHB17 enhances stress tolerance by coordinating photosynthesis associated nuclear gene and ATSIG5 expression in response to abiotic stress. Sci. Rep. 2017, 7, 45492. [CrossRef]

49. Robles, P.; Núñez-Delegido, E.; Ferrández-Ayela, A.; Sarmiento-Mañús, R.; Micol, J.L.; Quesada, V. Arabidopsis mTERF6 is required for leaf patterning. Plant Sci. 2018, 266, 117-129. [CrossRef]

50. Danilova, M.N.; Kudryakova., N.V.; Andreeva, A.A.; Pojidaeva, E.S.; Kuznetsov, V.V. Differential impact of heat stress on the expression of chloroplast-encoded genes. Plant Physiol. Biochem. 2018, 129, 90-100. [CrossRef]

51. Pfalz, J.; Pfannschmidt, T. Essential nucleoid proteins in early chloroplast development. Trends Plant Sci. 2013, 18, 186-194. [CrossRef] [PubMed]

52. Yamburenko, M.V.; Zubo, Y.O.; Börner, T. Abscisic acid affects transcription of chloroplast genes via protein phosphatase 2C-dependent activation of nuclear genes: Repression by guanosine- $3^{\prime}-5^{\prime}$-bisdiphosphate and activation by sigma factor 5. Plant J. 2015, 82, 1030-1041. [CrossRef] [PubMed]

53. Yamburenko, M.V.; Zubo, Y.O.; Vanková, R.; Kusnetsov, V.V.; Kulaeva, O.N.; Börner, T. Abscisic acid represses the transcription of chloroplast genes. J. Exp. Bot. 2013, 64, 4491-4502. [CrossRef] [PubMed]

54. Danilova, M.N.; Andreeva, A.A.; Doroshenko, A.S.; Kudryakova, N.V.; Kuznetsov, V.V.; Kusnetsov, V.V. Phytohormones Regulate the Expression of Nuclear Genes Encoding the Components of the Plastid Transcription Apparatus. Dokl. Biochem. Biophys. 2018, 478, 25-29. [CrossRef] [PubMed]

55. Takahashi, K.; Kasai, K.; Ochi, K. Identification of the bacterial alarmone guanosine $5^{\prime}$-diphosphate 3'-diphosphate (ppGpp) in plants. Proc. Natl. Acad. Sci. USA 2004, 101, 4320-4324. [CrossRef] [PubMed] 
56. Sato, M.; Takahashi, K.; Ochiai, Y.; Hosaka, T.; Ochi, K.; Nabeta, K. Bacterial alarmone, guanosine $5^{\prime}$-diphosphate $3^{\prime}$-diphosphate (ppGpp), predominantly binds the beta' subunit of plastid-encoded plastid RNA polymerase in chloroplasts. ChemBioChem 2009, 10, 1227-1233. [CrossRef]

57. Choudhury, F.K.; Rivero, R.M.; Blumwald, E.; Mittler, R. Reactive oxygen species, abiotic stress and stress combination. Plant J. 2017, 90, 856-867. [CrossRef]

58. Štefanic, P.P.; Koffler, T.; Adler, G.; Bar-Zvi, D. Chloroplasts of salt-grown Arabidopsis seedlings are impaired in structure, genome copy number and transcript levels. PLoS ONE 2013, 8, e82548.

59. Huang, G.T.; Ma, S.L.; Bai, L.P.; Zhang, L.; Ma, H.; Jia, P.; Liu, J.; Zhong, M.; Guo, Z.F. Signal transduction during cold, salt, and drought stresses in plants. Mol. Biol. Rep. 2012, 39, 969-987. [CrossRef]

60. Quesada, V.; Sarmiento-Mañús, R.; González-Bayón, R.; Hricová, A.; Pérez-Marcos, R.; Graciá-Martínez, E.; Medina-Ruiz, L.; Leyva-Díaz, E.; Ponce, M.R.; Micol, J.L. Arabidopsis RUGOSA2 encodes an mTERF family member required for mitochondrion, chloroplast and leaf development. Plant J. 2011, 68, 738-753. [CrossRef]

61. Robles, P.; Micol, J.L.; Quesada, V. Arabidopsis MDA1, a nuclear-encoded protein, functions in chloroplast development and abiotic stress responses. PLoS ONE 2012, 7, e42924. [CrossRef]

62. Schweer, J.; Loschelder, H.; Link, G. A promoter switch that can rescue a plant sigma factor mutant. FEBS Lett. 2006, 580, 6617-6622. [CrossRef] [PubMed]

63. Tadini, L.; Peracchio, C.; Trotta, A.; Colombo, M.; Mancini, I.; Jeran, N.; Costa, A.; Faoro, F.; Marsoni, M.; Vannini, C.; et al. GUN1 influences the accumulation of NEP-dependent transcripts and chloroplast protein import in Arabidopsis cotyledons upon perturbation of chloroplast protein homeostasis. Plant J. 2020, 101, 1198-1220. [CrossRef] [PubMed]

64. Sun, X.; Feng, P.; Xu, X.; Guo, H.; Ma, J.; Chi, W.; Lin, R.; Lu, C.; Zhang, L. A chloroplast envelope-bound PHD transcription factor mediates chloroplast signals to the nucleus. Nat. Commun. 2011, 2, 477. [CrossRef] [PubMed]

65. Livak, K.J.; Schmittgen, T.D. Analysis of relative gene expression data using real-time quantitative PCR and the 2(-Delta Delta C(T)). Methods 2001, 25, 402-408. [CrossRef]

66. Moschopoulos, A.; Derbyshire, P.; Byrne, M.E. The Arabidopsis organelle-localized glycyl-tRNA synthetase encoded by EMBRYO DEFECTIVE DEVELOPMENT1 is required for organ patterning. J. Exp. Bot. 2012, 63, 5233-5243. [CrossRef] 